\title{
A STUDY ON THE EFFECT OF ALOE VERA EXTRACT ON THE MOTOR AND EXPLORATORY ACTIVITIES IN NORMAL HEALTHY RATS
}

\author{
HAMDY M. EMBARK ${ }^{1}$ and ABDELMONEIM K. ABDALLA ${ }^{2}$ \\ ${ }^{1}$ Department of Animal Physiology, Faculty of Veterinary Medicine, South Valley University, Qena \\ 83523, Egypt \\ ${ }^{2}$ Department of Food Science, Faculty of Agriculture, South Valley University, Qena 83523, Egypt
}

Received: 30 September 2019; Accepted: 27 October 2019

\begin{abstract}
Aloe vera (AV) has been used in folk medicine for thousands of years, which has led researchers to study its various health benefits. The aim of this study was to evaluate the effect of AV extract on the motor and exploratory activities in normal healthy rats. The open-field test (OFT) was used to provide a quantitative measurement of the animal motor and exploratory activities. The rats were weighed and randomly divided into three groups (six rats in each) identified as: control group (rats received distilled water (DW)), AV $10 \%$ group (rats received AV extract 10\%), and AV 20\% group (rats received AV extract 20\%). All rats were administered DW or AV extracts by oral gavage once daily for 2 weeks at constant doses $(2 \mathrm{ml} / 100 \mathrm{~g}$ body weight $)$ among groups. The OFT was performed immediately after 2 weeks using LE8811 Actimeter PanLAB device. The results showed that oral consumption $10 \%$ and $20 \%$ of AV extract slightly reduced rats' global \& locomotor activities, stereotyped movements, distance traveled, and time spent in the fast movements in the OFT. Interestingly, oral consumption $10 \%$ and $20 \%$ of AV extract completely abolished central rats' rearing activity (exploration) and slightly increased resting time. Additionally, oral consumption of $10 \%$ and $20 \%$ of AV extract markedly reduced central permanence time and number of entries to center of the arena. However, only oral consumption of $10 \% \mathrm{AV}$ extract markedly reduced latency to first entry to center of the arena. Under our experimental conditions, these findings lead to the conclusion that $\mathrm{AV}$ extract possesses mild sedative and anxiolytic activities in concentration-dependent manner. Further studies are needed to assess these findings using different doses/concentrations of $\mathrm{AV}$ extract and other behavioral tests in rats.
\end{abstract}

Keywords: Aloe vera; Anxiety; Sedation; Rats

\section{INTRODUCTION}

Aloe vera $(\mathrm{AV})$ is a hardy succulent plant belonging to the family Aloaceae (Pathak and Sharma, 2019). The leaves of the AV plant rise from the base in the rosette pattern (Volkov and Shtessel, 2017). Each AV leaf is composed of three main layers: (i) An inner gel containing 99\% water, and the remaining part made of amino acids, glucomannans, sterols, lipids, and vitamins; (ii) The middle layer is made of latex, which is the bitter yellow sap containing anthraquinones and glycosides; and (iii) The outer thick layer, or rind, has protective function and synthesizes proteins and carbohydrates (Surjushe et al., 2008).

The AV, a magical plant, is widely used in the traditional herbal medicine of Egypt, China, India, Japan, and worldwide (Marshall, 1990; Park and Lee,

Corresponding author: Hamdy M. Embark E-mail address: h.embark@vet.svu.edu.eg Present address: Department of Animal Physiology, Faculty of Veterinary Medicine, South Valley University, Qena 83523 , Egypt
2006; Akev et al., 2011; Upton et al., 2012; Kumar et al., 2019). The medicinal benefits associated with AV have been attributed to the polysaccharides found in internal leaf aloe gel (Radha and Laxmipriya, 2014). Also, there is a synergistic effect with compounds contained in the whole leaf extracts beyond the medicinal properties of the AV plant (Eshun and He, 2004; Yohannes, 2018). Today, AV extract is widely used in medicine worldwide. It has antiinflammatory, antibacterial, antioxidant, and immune stimulating effects (Prabjone et al., 2006; Sahu et al., 2013).

Anxiety is a frequent negative emotional state characterized by feelings of worry and accompanied by specific behavioral manifestations (Nuss, 2015). Hall (1934) originally described the open-field test (OFT) for the study of emotionality in rats. The procedure consists of subjecting an animal to a novel environment from which escape is prevented by surrounding walls (Doukkali et al., 2016). Oral consumption of AV gel may also have sedative and anxiolytic effects in rodents. In an effort to identify the possible sedative and anxiolytic effects of AV 
extract, OFT has been used to investigate the motor and exploratory activities in normal healthy rats (Belzung, 1999; Prut and Belzung, 2003).

The aim of the current study was to evaluate the effects of AV extract on motor and exploratory activities in the open-field arena, as indicators representing $\mathrm{AV}$-mediated sedation and relaxation in a rat model.

\section{MATERIALS AND METHODS}

\section{Ethical Approval}

Animal handling and experimentation were performed in line with approved Institutional Animal Care and Use Committee (IACUC\#: 12-214) protocols at the South Valley University (Qena, Egypt) and complied with the ethical standards established by the Egyptian animal welfare laws and policies and followed the national authority (Ministry of Higher Education and Scientific Research, Egypt) guidelines for the detention, use and the ethical treatment of laboratory animals. Also, all animal protocols were approved by the Animal Use Subcommittee and by the Research and Ethical Review Committee of the Faculty of Veterinary Medicine, South Valley University.

\section{Experimental Animals}

Adult male Wistar albino rats were originally obtained from animal care facility at the Faculty of Medicine, Assiut University (Assiut, Egypt) and subsequently maintained in the animal care facility at the Faculty of Veterinary Medicine, South Valley University. Animals (6 per cage) were kept in the laboratory at $22 \pm 2^{\circ} \mathrm{C}$ with $60 \%$ relative humidity under a $12 \mathrm{~h} \mathrm{light/dark}$ cycle for 2 weeks prior to experimentation. Tap water and food pellets were always freely available.

\section{Preparation of Aloe vera Extract}

The fresh AV plant leaves was selected to derive crude gel. The gel collected as described in the study of Oyeyemi and Ajani (2015). Briefly, the leaf surfaces were thoroughly washed with tap water and later with distilled water to remove traces of dirt and soil. The fleshy mass of the AV was carefully opened by cutting the sharp edges. The gel was funnelled into a sterile beaker. 10 and $20 \mathrm{~g}$ of $\mathrm{AV}$ gel were weighed using a digital microsensitive scale. Each of these was then diluted with $100 \mathrm{ml}$ of distilled water to constitute 10 and 20 percentage $(\mathrm{m} / \mathrm{v})$ AV concentrations respectively. These were gently processed with a kitchen blender to achieve homogenous solution. This liquid was kept for $20 \mathrm{~min}$ to settle and later sieved using Whatman filter paper (No. 1) to obtain a particulate-free gel aqueous extract. The AV gel aqueous extract was freshly prepared every time before use. It contained all the functional ingredients of the crude gel in the same proportion as it appears in the leaf.

\section{Experimental Design}

Eighteen male Wistar albino rats (12 weeks old and 200-250 g weight) were used in this study. The protocol used in the present study is the same as described previously (Nurliyani et al., 2014; Moustafa et al., 2015). The rats were randomly divided into three experimental groups (six rats per group) as follows:

Group I (Control): rats were gavaged with distilled water ( $20 \mathrm{ml} / \mathrm{kg}$ body weight), once daily for fourteen consecutive days.

Group II (AV 10\%): rats were gavaged with 10\% Aloe vera extract ( $20 \mathrm{ml} / \mathrm{kg}$ body weight), once daily for fourteen consecutive days.

Group III (AV 20\%): rats were gavaged with $20 \%$ Aloe vera extract ( $20 \mathrm{ml} / \mathrm{kg}$ body weight), once daily for fourteen consecutive days.

\section{Behavioral Testing}

All rats were monitored daily by research staff beginning two weeks prior to the experiment. Before testing, rats were handled once daily for one week to acclimate them to gentle manipulation. Any environmental or physical stress was avoided in order to habituate the rats to manipulation for behavioral testing. The apparatus used in behavioral testing was thoroughly cleaned after each test session with a lightly wet cloth and then dry it with a dry cloth.

\section{Open-Field Test}

At the end of 14 day's test period, the animals were evaluated regarding motor and exploratory activities in a novel environment using an infrared LE8811 Actimeter system and measured using ActiTrack software (Panlab, Barcelona, Spain) (Mantha et al., 2013). The open-field chamber consisted of a $45 \mathrm{~cm}$ (width) $\times 45 \mathrm{~cm}$ (depth) arena of black plexiglass enclosed with four clear acrylic walls $(35 \mathrm{~cm}$ in height), as well as an infrared frame that produced a $16 \times 16$ grid of intersecting beams used to track the movement of each rat (Fig. 1A). Infrared beam-break data were used to calculate motor and exploratoryactivities. Movement data were analyzed by dividing the arena into an outer, $11.25 \mathrm{~cm}$-wide periphery zone and an interior, $22.5 \times 22.5 \mathrm{~cm}$ central zone (Fig. 1B). This procedure allows the study of different anxietyrelated parameters in rats (Simon et al., 1994).

Behavioral testing was carried out between the hours of 07:30 and 12:30 in order to reduce any diurnal fluctuations. The apparatus was placed in a room homogeneously illuminated at $400 \mathrm{~lx}$. Each rat was placed in the same corner of the arena when beginning the trial, and was allowed to freely explore for 10 minutes. This minimized stress to the animals. Measurements were only recorded during the final 5 min (first $5 \mathrm{~min}$ was used only for animal acclimatization). The following parameters were analyzed: (i) global \& locomotor activities, 
stereotyped movements, mean velocity/speed, total distance travelled, and number of rearing in each user-defined zones; (ii) time spent in fast $(>5 \mathrm{~cm} / \mathrm{s}) \&$ slow $(<5 \mathrm{~cm} / \mathrm{s})$ movements or in rest $(0-2 \mathrm{~cm} / \mathrm{s})$; (iii)

A

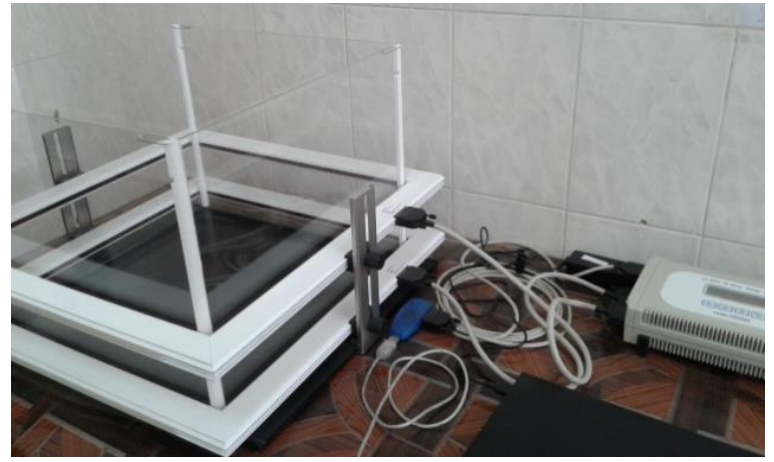

latency time to enter the center zone, number of entries into center zone, and permanence time in each zone. At the end of the testing, the rat was removed and returned to its home cage.

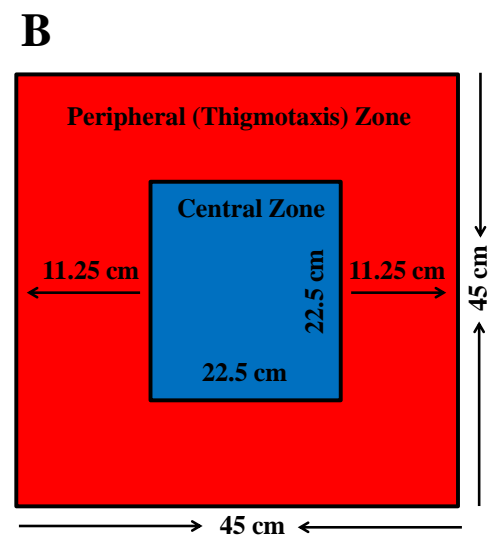

Fig. 1: Apparatus used to assess motor and exploratory activities of rats. (A) An open-field chamber with a sample ActiTrack real-time tracking output. Lower frame is used to track motor activity, while the upper frame tracks number of rearing (exploratory activity). (B) Schematic of zones in open-field arena with separation of the peripheral zone (red) and the central zone (blue).

\section{Statistical Analysis}

The results are presented as mean \pm standard errors of the mean (SEM); $n$ represents the number of animals in each group. Data analyses were performed with Origin 6.0 (OriginLab Corp., Northampton, MA, USA) software for Windows. Group means for all measures were compared using unpaired Student's $t$ test (for two group comparisons) to verify significant differences between groups. Differences were considered statistically significant when a minimum value of $P$ less than 0.05 .

\section{RESULTS}

\section{Effect of oral consumption of Aloe vera extract on} the rats' global activity

Global activity is the sum total of locomotor and stereotypic activities. After 2 weeks, oral consumption $10 \%$ of Aloe vera extract ( $2 \mathrm{ml} / 100 \mathrm{~g} \mathrm{~b}$

A

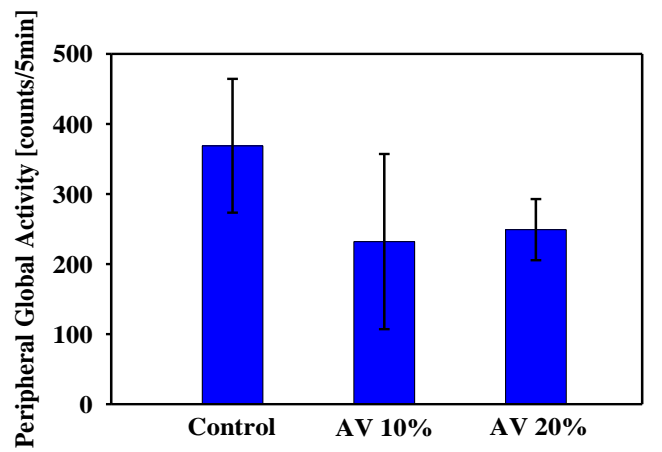

wt/day) decreased the peripheral and central global activities $\quad(232.00 \pm 125.08$ and 24.50 \pm 14.50 , respectively), but this did not reach statistical significance when compared with the control animals receiving only distilled water $(368.67 \pm 95.52$ and $50.80 \pm 26.66$, respectively) in a novel open-field environment (Fig. 2A,B)

Similarly, oral gavage $20 \%$ of Aloe vera extract (2 $\mathrm{ml} / 100 \mathrm{~g} \mathrm{~b} \mathrm{wt} /$ day) for two consecutive weeks was also associated with decreased peripheral and central global activities $(249.00 \pm 43.67$ and $3.33 \pm 1.20$, respectively), but statistically not significant, compared to the control group $(368.67 \pm 95.52$ and $50.80 \pm 26.66$, respectively), in the open-field arena (Fig. 2A,B). It seems likely that the concentrationdependent effect of Aloe vera extract on global activity is very sensitive especially in the central area of the open-field arena.

\section{$\mathbf{B}$}

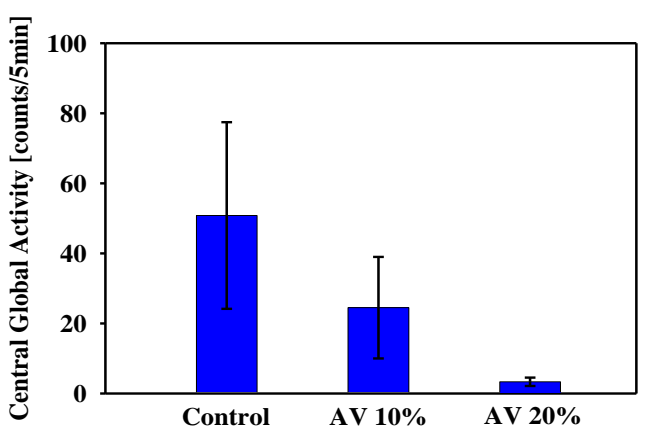

Fig. 2: The rats' global activity in a novel open-field environment. Mean $( \pm \mathrm{SEM})$ infrared beam breaks of control and treated rats two weeks after oral distilled water/Aloe vera consumption respectively over a 5minute test period ( $n=6$ rats per group) in the peripheral (A) and central (B) zones of the open-field arena. 


\section{Effect of oral consumption of Aloe vera extract on} the rats' locomotor activity

Locomotor movements include movements with displacement. After 2 weeks, oral consumption $10 \%$ of Aloe vera extract decreased the peripheral and central locomotor activities $(214.50 \pm 116.61$ and $24.00 \pm 14.00$, respectively), but this did not reach statistical significance when compared with the control animals $(345.33 \pm 89.79$ and $47.20 \pm 24.20$, respectively) in a novel open-field environment (Fig. 3A,B).
Likewise, oral gavage $20 \%$ of Aloe vera extract for two consecutive weeks was also associated with a decrease in the peripheral and central locomotor activities (232.40 \pm 40.58 and 3.00 \pm 1.00 , respectively), but statistically not significant, compared to the control group $(345.33 \pm 89.79$ and 47.20 \pm 24.20 , respectively), in the open-field arena (Fig. 3A,B). Aloe vera extract decreased the locomotor activity of rats in concentration-dependent manner, particularly in center zone.
A

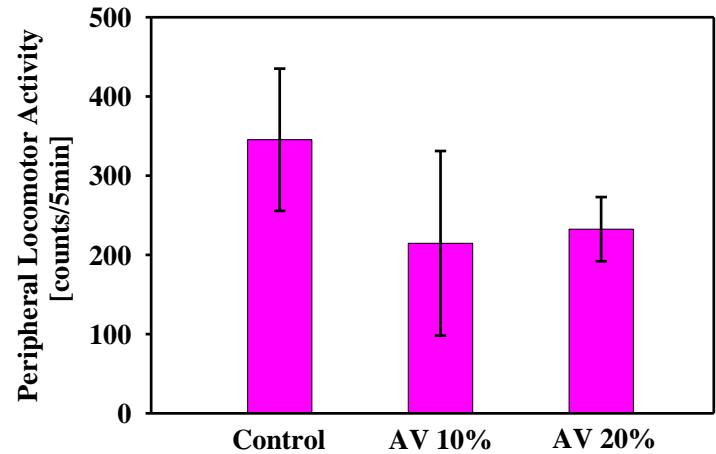

B

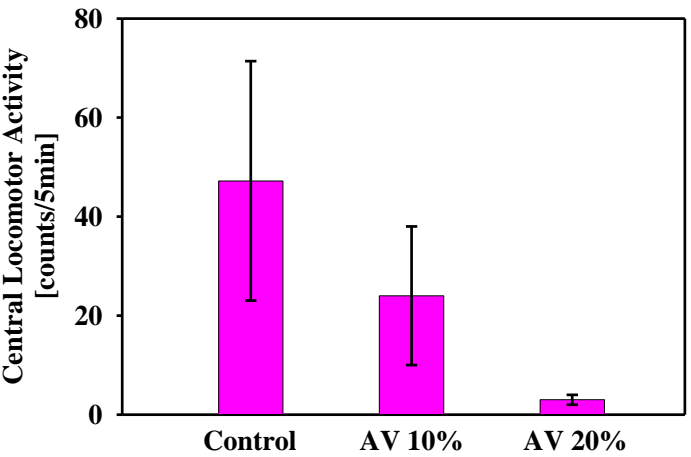

Fig. 3: The rats' locomotor activity in a novel open-field environment. Mean $( \pm \mathrm{SEM})$ infrared beam breaks of control and treated rats two weeks after oral distilled water/Aloe vera consumption over a 5-minute test period ( $n=6$ rats per group) in the peripheral (A) and central (B) zones of the open-field arena.

Effect of oral consumption of Aloe vera extract on the rats' stereotyped movements

Stereotyped movements include movements without displacement, i.e. eating and cleaning movements. After 2 weeks, oral consumption $10 \%$ of Aloe vera extract decreased the peripheral and central stereotyped movements $(17.50 \pm 8.63$ and $0.50 \pm 0.50$, respectively), but this did not reach statistical significance when compared with the control animals $(23.33 \pm 6.04$ and $3.60 \pm 2.46$, respectively) in a novel open-field environment (Fig. 4A,B).

A

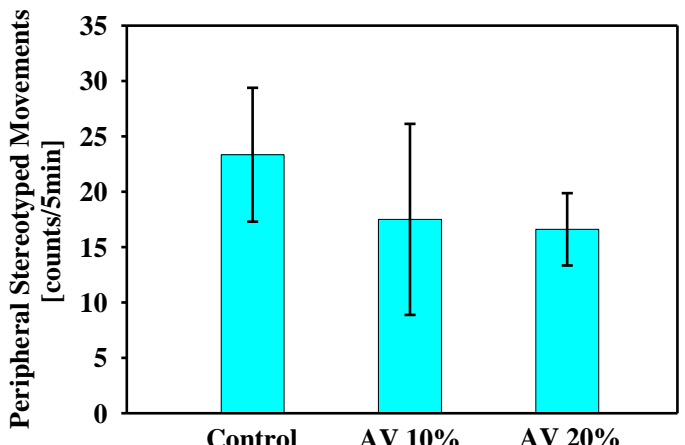

In the same way, oral gavage $20 \%$ of Aloe vera extract for two consecutive weeks was associated with a decrease in the peripheral and central stereotyped movements $(16.60 \pm 3.27$ and $0.33 \pm 0.33$, respectively), but statistically not significant, compared to the control group $(23.33 \pm 6.04$ and $3.60 \pm 2.46$, respectively), in the open-field arena (Fig. 4A,B). Aloe vera extract decreased the stereotyped movements of rats in concentration-dependent manner, particularly in center zone.

\section{B}

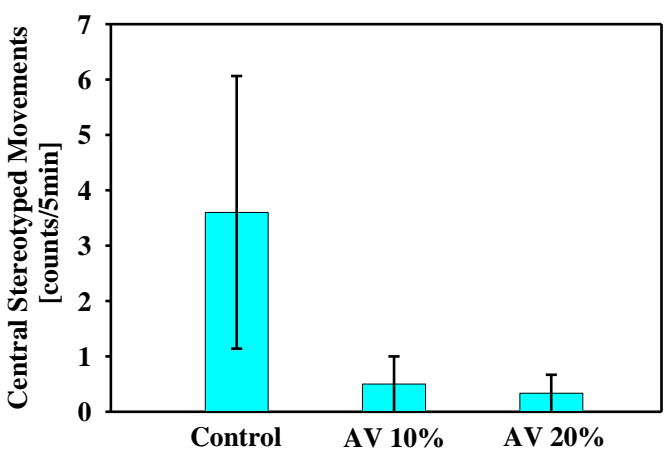

Fig. 4: The rats' stereotyped movements in a novel open-field environment. Mean $( \pm$ SEM) infrared beam breaks of control and treated rats two weeks after oral distilled water/Aloe vera consumption respectively over a 5 -minute test period ( $n=6$ rats per group) in the peripheral (A) and central (B) zones of the open-field arena. 
Effect of oral consumption of Aloe vera extract on the rats' movements velocity/speed

After 2 weeks, oral consumption $10 \%$ and $20 \%$ of Aloe vera extract markedly reduced the peripheral mean speed $(1.11 \pm 0.74$ and $1.06 \pm 0.22$, respectively), but this did not reach statistical significance when compared with the control animals $(1.82 \pm 0.52)$ in a novel open-field environment (Fig. 5A).

\section{A}

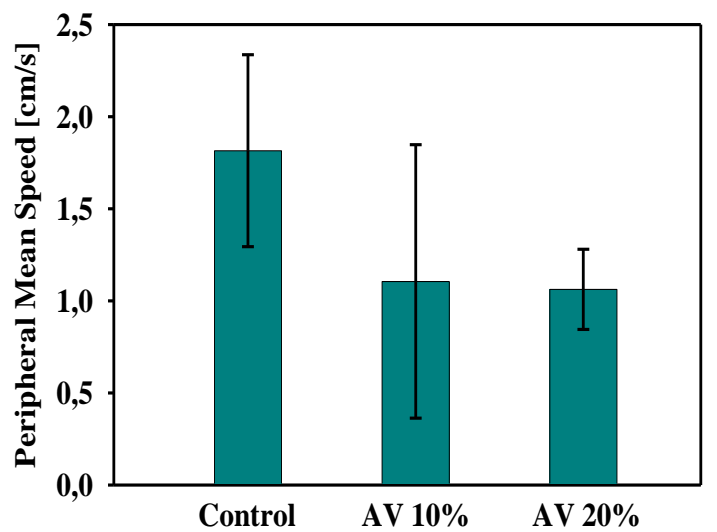

In contrast, oral gavage $10 \%$ and $20 \%$ of Aloe vera extract for two consecutive weeks was associated with slight changes in the central mean speed (10.94 \pm 9.19 and $12.86 \pm 5.12$, respectively), but statistically not significant, compared to the control group $(11.87 \pm 2.89)$, in the open-field arena (Fig. 5B).

\section{B}

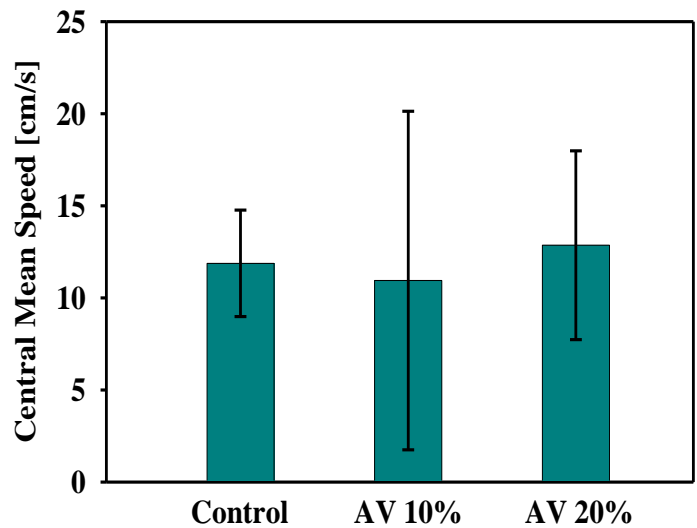

Fig. 5: The rats' speed in a novel open-field environment. Mean $( \pm$ SEM) average speed $(\mathrm{cm} / \mathrm{s})$ of control and treated rats two weeks after oral distilled water/Aloe vera consumption respectively over a 5-minute test period ( $n=6$ rats per group) in the peripheral (A) and central (B) zones of the open-field arena.

Effect of oral consumption of Aloe vera extract on the rats' distance travelled

After 2 weeks, oral consumption $10 \%$ of Aloe vera extract markedly reduced the peripheral and central moved distance $(328.13 \pm 219.30$ and $17.53 \pm 15.15$, respectively), but this did not reach statistical significance when compared with the control animals $(522.33 \pm 146.88$ and $70.75 \pm 36.58$, respectively) in a novel open-field environment (Fig. 6A,B).
Similarly, oral gavage $20 \%$ of Aloe vera extract for two consecutive weeks was associated with a marked decrease in the peripheral and central moved distance (317.96 \pm 65.32 and 5.20 \pm 2.96 , respectively), but statistically not significant, compared to the control group $(522.33 \pm 146.88$ and $70.75 \pm 36.58$, respectively), in the open-field arena (Fig. 6A,B). Aloe vera extract reduced the moved distance of rats in concentration-dependent manner, particularly in central zone.
A

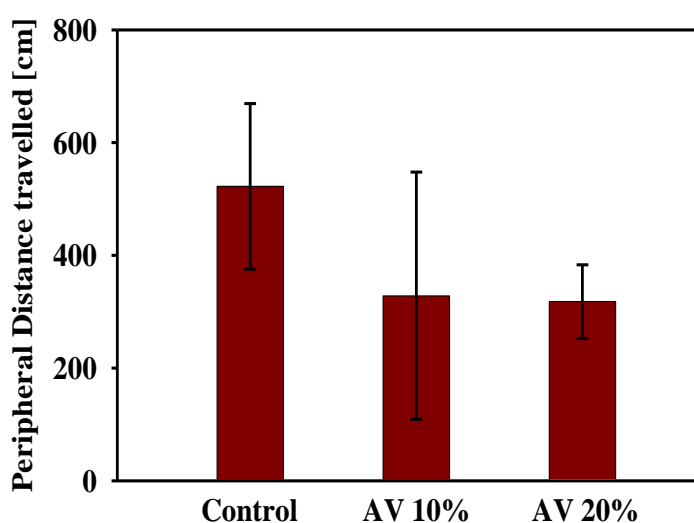

B

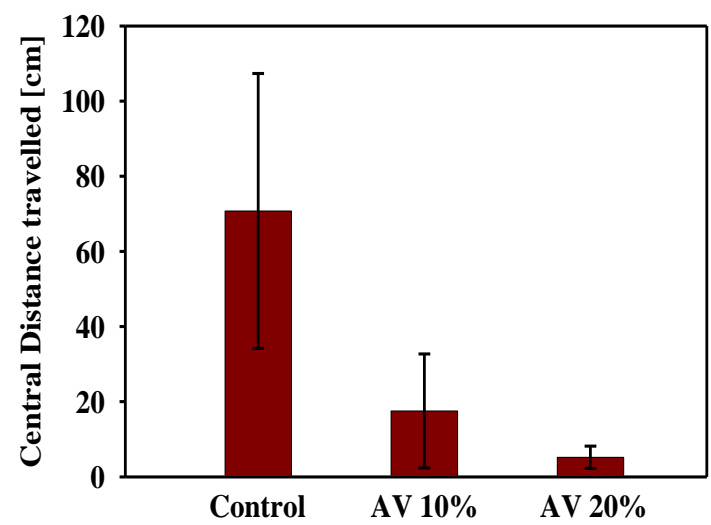

Fig. 6: Distance travelled by rats in a novel open-field environment. Mean $( \pm \mathrm{SEM})$ distance travelled $(\mathrm{cm})$ by control and treated rats two weeks after oral distilled water/Aloe vera consumption respectively over a 5minute test period ( $n=6$ rats per group) in the peripheral (A) and central (B) zones of the open-field arena. 
Effect of oral consumption of Aloe vera extract on the rats' movements and resting

After 2 weeks, oral consumption $10 \%$ and $20 \%$ of Aloe vera extract markedly reduced the time spent in the fast movements $(21.80 \pm 17.38$ and $21.48 \pm 5.83$, respectively), but this did not reach statistical significance when compared with the control animals (46.23 \pm 15.03$)$ (Fig. 7A). However, oral consumption $10 \%$ and $20 \%$ of Aloe vera extract was associated with slight changes in the slow-movements time (42.33 \pm 14.22 and $50.48 \pm 11.16$, respectively), when compared with the control animals $(59.90 \pm 11.91)$ in a novel open-field environment (Fig. 7B).

In contrast, oral gavage $10 \%$ and $20 \%$ of Aloe vera

A

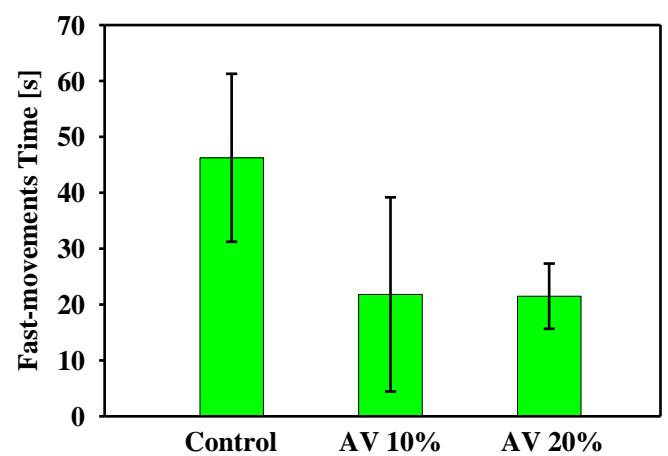

C

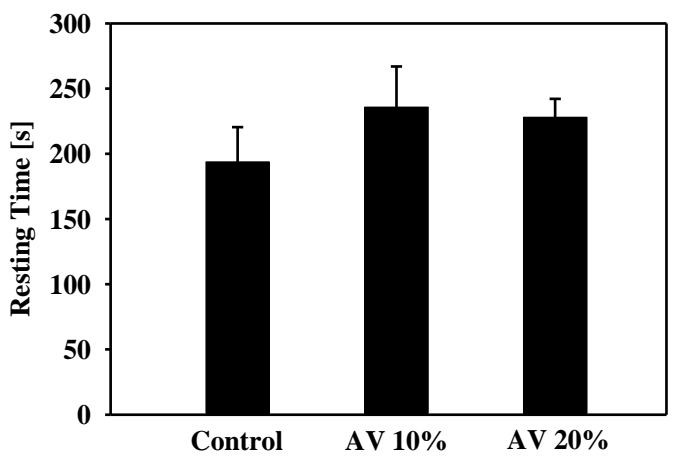

extract for two consecutive weeks slightly increased the rest time $(235.87 \pm 31.11$ and $228.04 \pm 14.02$, respectively), compared to the control group (193.87 \pm 26.58$)$ in the open-field arena but this did not reach statistical significance (Fig. 7C).

In turn, oral consumption $10 \%$ and $20 \%$ of Aloe vera extract apparently reduced the percentage of time that the rats spent in fast movements with slight effect on the percentage of time spent in slow movements, compared with the control animals in a novel openfield environment. However, the percentage of time that the rats spent in resting was apparently increased in rats received $10 \%$ or $20 \%$ Aloe vera extract compared to control group (Fig. 7D).

B

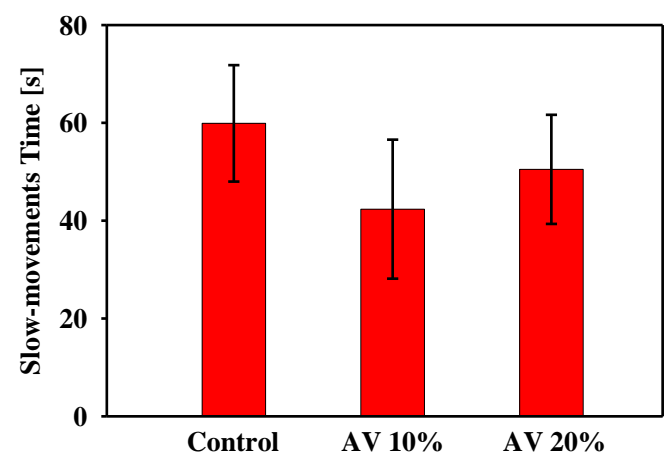

D

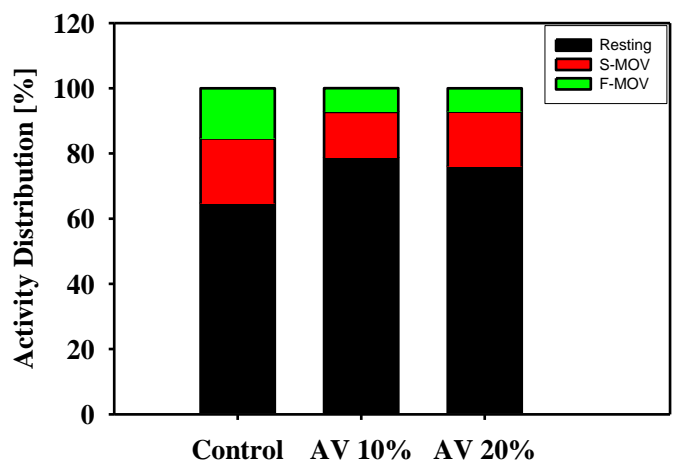

Fig. 7: Time spent in fast and slow movements or in resting in the open-field arena. Mean $( \pm S E M)$ time spent in fast (A) and slow movements (B) or in inactivity (C) Activity distribution (D), as the percentage of total time ( 5 minutes), of the control and treated rats two weeks after oral distilled water/Aloe vera consumption respectively over a 5-minute test period ( $n=6$ rats per group) in the open-field arena.

Effect of oral consumption of Aloe vera extract on the rats' rearing activity

Rearing (i.e. standing on rear limbs) is a common measure of exploratory activity used in the open-field test. After 2 weeks, oral consumption $10 \%$ of Aloe vera extract was associated with a non-significant decrease in number of rearing in the peripheral zone (3.67 \pm 2.29$)$, compared to the control group (5.00 \pm 1.93$)$, in this behavioral experimental model in rats (Fig. 8A). However, oral consumption $20 \%$ of Aloe vera extract for two consecutive weeks was not associated with changes in the number of rearing in the peripheral zone $(5.60 \pm 2.14)$, compared to the control group (Fig. 8A).

Interestingly, oral gavage $10 \%$ and $20 \%$ of Aloe vera extract for two consecutive weeks completely abolished the rats' rearing activity in the central zone of the arena compared with the control group $(1.17 \pm 0.65)$ in a novel open-field environment (Fig. 8B). 
A

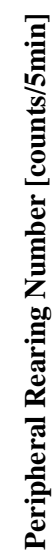

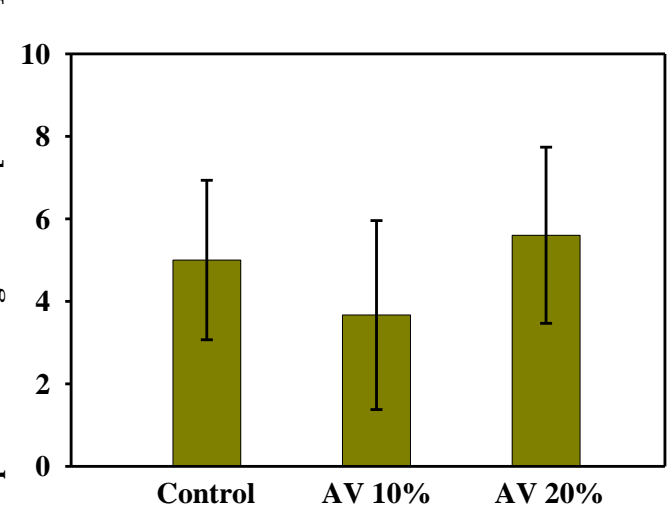

B

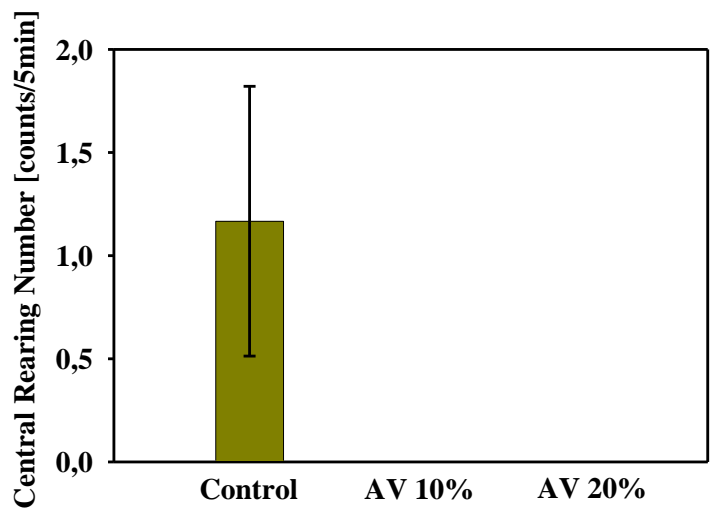

Fig. 8: Rearing activity scores of rats in the open-field test. Mean $( \pm \mathrm{SEM})$ number of rearing of control and treated rats two weeks after oral distilled water/Aloe vera consumption respectively over a 5-minute test period ( $n=6$ rats per group) in the peripheral (A) and central (B) zones of the open-field arena.

Effect of oral consumption of Aloe vera extract on the rats' entries to central zone

After 2 weeks, oral consumption $10 \%$ of Aloe vera extract markedly reduced the latency time to first enter the central zone $(19.40 \pm 19.40)$, but this did not reach statistical significance when compared with the control animals $(86.88 \pm 46.96)$ in a novel open-field environment (Fig. 9A). While, oral gavage $20 \%$ of Aloe vera extract ( $2 \mathrm{ml} / 100 \mathrm{~g} \mathrm{~b} \mathrm{wt} /$ day) for two consecutive weeks was associated with slight changes in the latency time to first enter the central zone

\section{A}

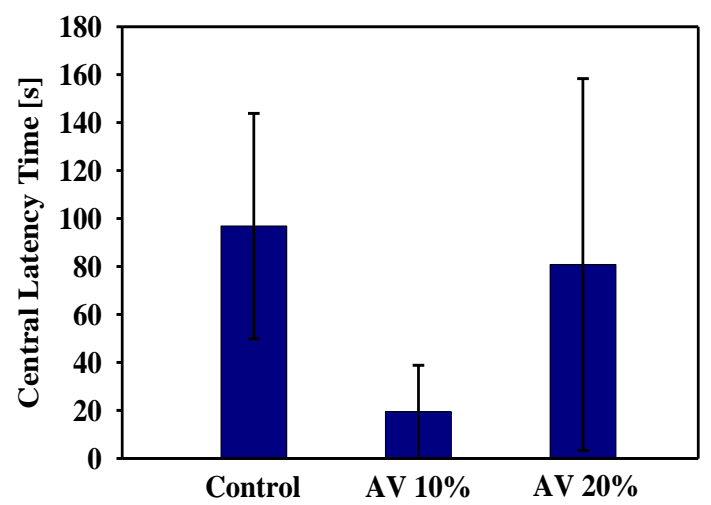

(80.80 \pm 77.52 ), compared to the control animals (Fig. 9A).

Additionally, oral gavage $10 \%$ and $20 \%$ of Aloe vera extract for two consecutive weeks markedly reduced the number of entries into the central zone $(1.33 \pm 1.33$ and $0.80 \pm 0.58$, respectively), but this did not reach significance when compared with the control group (4.67 \pm 2.36$)$ concentration-dependent manner (Fig. 9B).

B

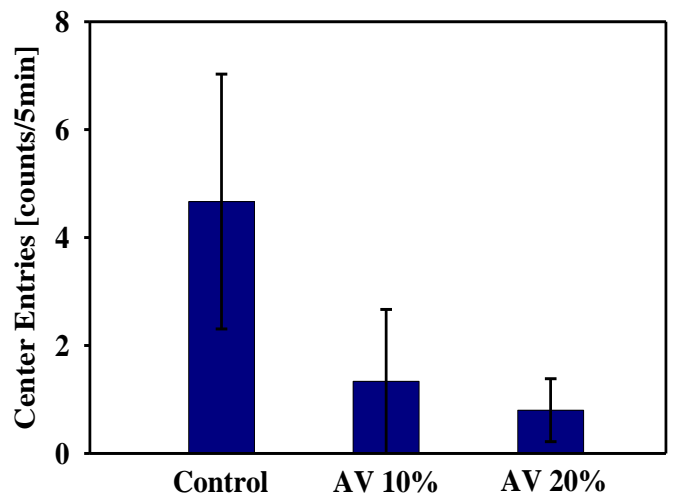

Fig. 9: Duration and number of entries into the central zone of the open-field arena. Mean ( \pm SEM) latency time in seconds to first entry (A) and the number of entries $(\mathbf{B})$ into the central zone by control and treated rats two weeks after oral distilled water/Aloe vera consumption respectively over a 5 -minute test period $(n=6$ rats per group) into the center zone of the open-field arena.

Effect of oral consumption of Aloe vera extract on the rats' permanence time

Permanence time is the total time in seconds spent in the specified zones of the arena regardless of the number of entries. Oral consumption $10 \%$ and $20 \%$ of Aloe vera extract for two consecutive weeks was not associated with changes in the time spent in the peripheral zone $(298.03 \pm 1.29$ and $299.60 \pm 0.23$, respectively), compared to the control animals
(291.77 \pm 5.21$)$, in this behavioral experimental model in rats (Fig. 10A).

On the other hand, oral gavage $10 \%$ and $20 \%$ of Aloe vera extract markedly reduced the time spent in the central zone $(1.97 \pm 1.23$ and $0.40 \pm 0.23$, respectively), but this did not reach significance when compared with the control group $(8.23 \pm 5.21)$ in concentrationdependent manner (Fig. 10B). 


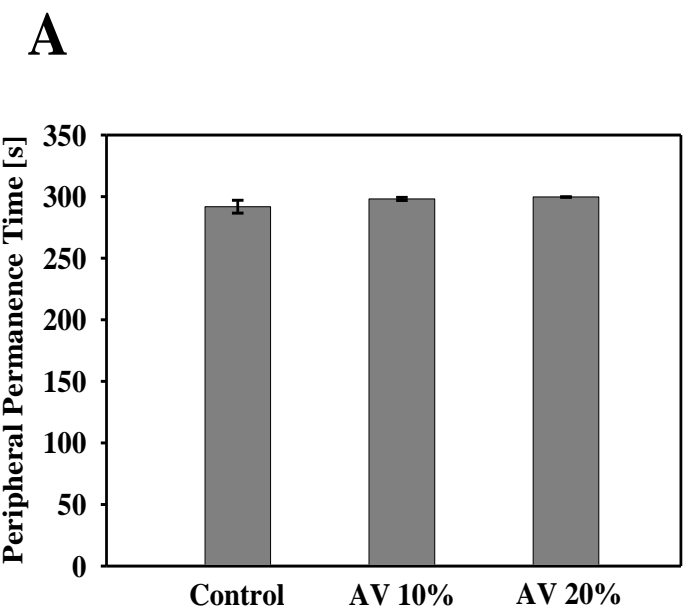

\section{B}

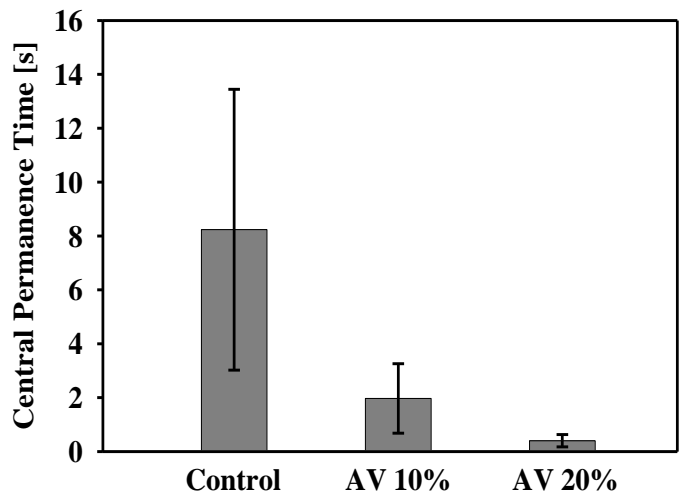

Fig. 10: Time of permanence in the different zones of the open-field arena. Mean $( \pm \mathrm{SEM})$ total time (s) spent in the peripheral (A) and central (B) zones of the open-field chamber by control and treated rats two weeks after oral distilled water/Aloe vera consumption respectively over a 5-minute test period ( $n=6$ rats per group).

\section{DISCUSSION}

Aloe vera $(\mathrm{AV})$ is a popular plant in traditional medicine and has multiple therapeutic benefits (Joseph and Raj, 2010; Thombre et al., 2019). Over the past decade, numerous studies carried out in animal models have revealed that AV may possess an important antidepressant and analgesic activities (Sultana and Najam, 2012; Halder et al., 2013). In the current study, we only focus on the precise impacts of AV extract consumption on motor and exploratory activities in normal healthy rats using open-field test (OFT). Measuring the animal's activity in a novel environment may highlight sedative and anxiolytic potentials of the AV extract (Moniruzzaman et al., 2019).

The OFT is an experimental procedure used for evaluation of general activity, locomotor, stereotypic movements, rearings or exploration in rodents (Hrnkova et al., 2007). The animal is placed in the center or close to the walls of the open-field arena and the activity of the animals was recorded via a computer program (Kas et al., 2008). For animal's activity assessment, the open-field arena is divided into two zones: the "central zone" and the "wall or peripheral zone" (Hart et al., 2010). Therefore, the general rats' activities \& movements, mean speed, total distance travelled, rearing \& entry numbers, rest $\&$ permanence time in selected zones, and latency to enter central zone can be easily measured (Lynch et al., 2011).

The present results showed that oral consumption $10 \%$ and $20 \%$ of AV extract for 2 weeks was associated with a slight decline in peripheral rats' activities and movements. Additionally, oral consumption $10 \%$ and $20 \%$ of AV extract markedly reduced fast-movements time and slightly increased time of inactivity in concentration-dependent manner. Alteration in motor activity in rats under OFT is considered as an index of sedative effect (Abdollahnejad et al., 2016). Therefore, AV extract may be having a mild sedative effect under our experimental condition.

In addition, the anxiolytic effect of AV extract was indicated by a reduction in the latency to enter the center (Donthula and Dholi, 2018). Indeed, our data also showed that oral consumption of AV extract only at concentration of $10 \%$ reduced latency time to enter the center of the arena compared to control and AV $20 \%$ groups. Oral consumption $10 \%$ and $20 \%$ of AV extract completely abolished central rearing or exploration of the rats. Taken together, AV extract may be having an anxiolytic effect in concentrationdependent manner.

It has been reported that $\mathrm{AV}$ is effective to treat various central nervous system (CNS) disorders such as multiple sclerosis (Mirshafiey et al., 2010) and convulsion (Rathor et al., 2014). The anticonvulsant and sedative activity of medicinal plants has frequently attributed to its active phytochemical's compounds such as flavonoids (Cho et al., 2012). Many of the neurotransmitters such as histamine, dopamine, norepinephrine, serotonin, glutamate, orexin and acetylcholine are involved in sleep-wake regulation (Van Erum et al., 2019). It should be mentioned, however, that the implication of any of the mentioned neurotransmitters needs further clarification as our study did not include any contributing examination.

\section{CONCLUSIONS}

The present study provides additional evidences which support sedative and anxiolytic effects of AV 
extract obtained by folk or traditional medicine. Examining different doses/concentrations of the AV extract and using other behavioral tests should be added. Further experiments are clearly required to determine precisely the specific mechanisms underlying these neurobiological changes in AVinduced sedation in a rat model.

\section{ACKNOWLEDGEMENTS}

The authors gratefully acknowledge all members and professors of the Department of Animal Physiology, Faculty of Veterinary Medicine, South Valley University, Qena, Egypt, and of Food Science Department, Faculty of Agriculture, South Valley University, Qena, Egypt, for their constant encouragement and kind help.

\section{GRANTS}

This work was supported by grant No. 2505 from the Science and Technology Development Fund (STDF), Egypt.

\section{DISCLOSURES}

The authors declare that there are no conflicts of interest regarding publication of this article.

\section{REFERENCES}

Abdollahnejad, F.; Mosaddegh, M.; Nasoohi, S.; Mirnajafi-Zadeh, J.; Kamalinejad, M. and Faizi, M. (2016): Study of Sedative-Hypnotic Effects of Aloe vera L. Aqueous Extract through Behavioral Evaluations and EEG Recording in Rats. Iran. J. Pharm. Res. 15, 293-300.

Akev, N.; Can, A. and Sutlupinar, N. (2011): Fifteen years of work on Aloe vera; In: The Second Euro-Med Conference on "Plant Natural Products: From Biodiversity to Bioindustry" (BioNat-II); 11-13 December: Alexandria, Egypt p. 20.

Belzung, C. (1999): Measuring exploratory behavior. In: Crusio, W.E., Gerlai, R.T. (Eds.), Handbook of Molecular Genetic Techniques for Brain and Behavior Research (Techniques in the Behavioral and Neural Sciences). Elsevier, Amsterdam, pp. 739-749.

Cho, S.; Yoon, M.; Kim, D.; Kim, J-S.; Yang, H.; Lee, C-H.; Kim, I-H.; Shimizu, M. and Han, D. (2012): Effect of the licorice flavonoid isoliquiritigenin on the sleep architecture and profile in mice. Food Science and Biotechnology. 21, 1221-1225.

Donthula, K.K. and Dholi, S.K. (2018): Evaluation of antipsychotic and anxiolytic activity of Aloe vera (ALOE BARBADENSIS MILLER) in rats. world journal of pharmaceutical research 7, 889-897

Doukkali, Z.; Taghzouti, K.; Bouidida, E.; Kamal, R.; Nadjmouddine, M.; Cherrah, Y. and Alaoui, $K$. (2016): Anxiety Behavior is reduced in the Balb/C Mice that Treated by Methanolic Extract of Urtica urens: An Elevated plus Maze and Open Field Analysis. Electronic Journal of Biology 12: 28-34.

Eshun, K. and He, Q. (2004): Aloe vera: A valuable ingredient for the food, pharmaceutical and cosmetic industries $-\mathrm{A}$ review, Crit. Rev. Food Sci. 44, 91-96.

Halder, S.; Mehta, A.K. and Mediratta, P.K. (2013): Aloe vera improves memory and reduces depression in mice. Nutr. Neurosci. 16, 250254.

Hall, C.S. (1934): Emotional behavior in the rat: I. Defecation and urination as measures of individual differences in emotionality. $\mathrm{J}$. Comp. Psychol. 18: 385-403.

Hart, P.C.; Bergner, C.L.; Smolinsky, A.N.; Dufour, B.D.; Egan, R.J.; Laporte, J.L. and Kalueff, A.V. (2010): Experimental models of anxiety for drug discovery and brain research. Methods Mol. Biol. 602: 299-321.

Hrnkova, M.; Zilka, N.; Minichova, Z.; Koson, P. and Novak, M. (2007): Neurodegeneration caused by expression of human truncated tau leads to progressive neurobehavioural impairment in transgenic rats. Brain Res. 1130: 206-213.

Joseph, B. and Raj, S.J. (2010): Pharmacognostic and phytochemical properties of Aloe vera Linnan overview. International Journal of Pharmaceutical Sciences Review and Research 4, 106-110.

Kas, M.J.; De Mooij-Van Malsen, A.J.; Olivier, B.; Spruijt, B.M. and van Ree, J.M. (2008): Differential genetic regulation of motor activity and anxiety-related behaviors in mice using an automated home cage task. Behav. Neurosci., 122: 769-776.

Kumar, R.; Singh, A.K.; Gupta, A.; Bishayee, A. and Pandey, A.K. (2019): Therapeutic potential of Aloe vera-A miracle gift of nature. Phytomedicine 60, 1-11.

Lynch, J.J.; 3rd, Castagné, V.; Moser, P.C. and Mittelstadt, S.W. (2011): Comparison of methods for the assessment of locomotor activity in rodent safety pharmacology studies. J. Pharmacol. Toxicol. Methods, 64: 74-80.

Mantha, K.; Kleiber, M. and Singh, S. (2013): Neurodevelopmental Timing of Ethanol Exposure May Contribute to Observed Heterogeneity of Behavioral Deficits in a Mouse Model of Fetal Alcohol Spectrum Disorder (FASD). Journal of Behavioral and Brain Science, 3: 85-99.

Marshall, J.M. (1990): Aloe vera gel: What is the evidence? Pharma J. 24, 360-362. 
Mirshafiey, A.; Aghily, B.; Namaki, S.; Razavi, A.; Ghazavi, A.; Ekhtiari, P. and Mosayebi, G. (2010): Therapeutic approach by Aloe vera in experimental model of multiple sclerosis. Immunopharmacol. Immunotoxicol. 32, 410415.

Moniruzzaman, M.; Bhattacharjee, P.S.; Pretty, M.R. and Hossain, M.S. (2016): Sedative and Anxiolytic-Like Actions of Ethanol Extract of Leaves of Glinus oppositifolius (Linn.) Aug. DC. Evidence-Based Complementary and Alternative Medicine 2016, 1-8.

Moustafa, M.A.; Ghareeb, D.A.; Hafez, E.E.; ElGamal, B. and El-Sadanii, M. (2015): LARGININE DOWN-REGULATED TNFALPHA GENE IN LPS INDUCED INFLAMMATION IN EXPERIMENTAL RATS. Ejpmr 2: 1-19.

Nurliyani, Kandarina, B.I.; Kusuma, S. and Trisnasari, Y.D. (2014): Goat Milk Yoghurt by Using Lacto-B Culture Modulates the Production of Tumor Necrosis Factor-Alpha and Interleukin-10 in Malnourished Rats. Korean J. Food Sci. Anim. Resour. 34, 88-98.

Nuss, P. (2015): Anxiety disorders and GABA neurotransmission: a disturbance of modulation. Neuropsychiatr. Dis. Treat. 11: 165-175.

Oyeyemi, M.O. and Ajani, O.S. (2015): Haematological parameters, semen characteristics and sperm morphology of male albino rat (wistar strain) treated with Aloe vera gel. Journal of Medicinal Plants Research. 9, 510-514.

Park, Y.I. and Lee, S.K. (2006): New Perspectives on Aloe, Springer: New York, USA 200 pp.

Pathak, D. and Sharma, R. (2019): REVIEW ON "ALOE VERA- MEDICINAL PLANT". IJARIIE 3, 661-671.

Prabjone, R.; Thong-Ngam, D.; Wisedopas, N.; Chatsuwan, T. and Patumraj, S. (2006): Antiinflammatory effects of Aloe vera on leukocyte-endothelium interaction in the gastric microcirculation of Helicobacter pylori-infected rats. Clinical hemorheology and microcirculation 35, 359-366.

Prut, L. and Belzung, C. (2003): The open field as a paradigm to measure the effects of drugs on anxiety-like behaviors: a review. Eur. J. Pharmacol. 463: 3-33.

Radha, M.H. and Laxmipriya, N.P. (2014): Evaluation of biological properties and clinical effectiveness of Aloe vera: A systematic review. J. Tradit. Complement. Med. 5, 21-26.

Rathor, N.; Arora, T.; Manocha, S.; Patil, A.N.; Mediratta, P.K. and Sharma, K.K. (2014): Anticonvulsant activity of Aloe vera leaf extract in acute and chronic models of epilepsy in mice. J. Pharm. Pharmacol. 66, 477-485.

Sahu, P.K.; Giri, D.D.; Singh, R.; Pandey, P.; Gupta, S.; Shrivastava, A.K. and Pandey, K.D. (2013): Therapeutic and medicinal uses of aloe vera: a review. Pharmacology \& Pharmacy 4, 599-610.

Simon, P.; Dupuis, R. and Costentin, J. (1994): Thigmotaxis as an index of anxiety in mice. Influence of dopaminergic transmissions. Behav. Brain Res. 61: 59-64.

Sultana, N. and Najam, R. (2012): Anxiolytic Activity of Aloe vera (L.) BURM.F Tested in Rodents. Pakistan Journal of Pharmacology 29, 7-15.

Surjushe, A.; Vasani, R. and Saple, D.G. (2008): Aloe vera: A short review. Indian J Dermatol. 53, 163-166.

Thombre, N.A.; Madhukar, G.S. and Subhash, C.K. (2019): A Review on Analgesic Herbals. IJTCM 4, 14-21.

Upton, R.; Axentiev, P. and Swisher, D. (2012): Aloe vera Leaf, Aloe vera Leaf Juice, Aloe vera Inner Leaf Juice, Aloe vera (L.) Burm. F: Standarts of Identitiy, Analysis and Quality Control; American Herbal Pharmacopoeia: Scotts Valley, CA 55 pp.

Van Erum, J.; Van Dam, D. and De Deyn, P.P. (2019): Alzheimer's disease: Neurotransmitters of the sleep-wake cycle. Neurosci. Biobehav. Rev. 105, 72-80.

Volkov, A.G. and Shtessel, Y.B. (2017): Electrotonic signal transduction between Aloe vera plants using underground pathways in soil: Experimental and analytical study. AIMS Biophysics 4, 576-595.

Yohannes, G. (2018): Review on Medicinal Value of Aloe Vera in Veterinary Practice. Biomed. J. Sci. \& Tech. Res. 6, 4970-4975. 


\section{دراسة عن تأثير مستخلص الصبّار على الأنثطة الحركية في الفئران السليمة الطبيعية$$
\text { حمدي أمبارك ، عبل المنعم عبد الله }
$$

E-mail: h.embark@vet.svu.edu.eg Assiut University web-site: www.aun.edu.eg

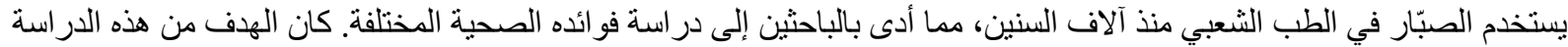

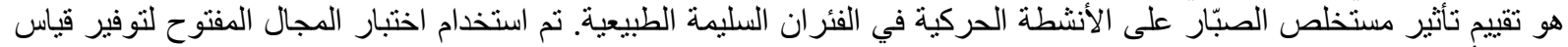

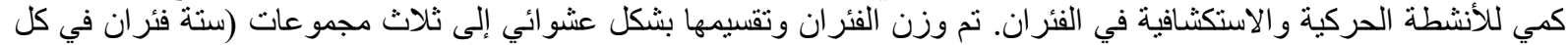

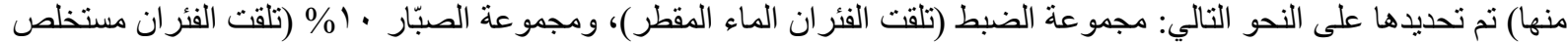

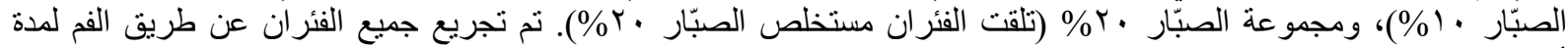

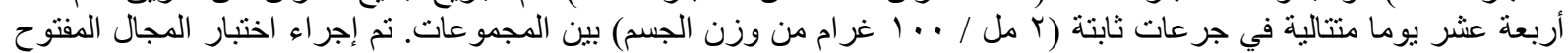

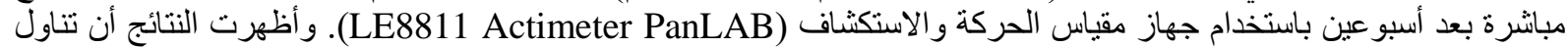

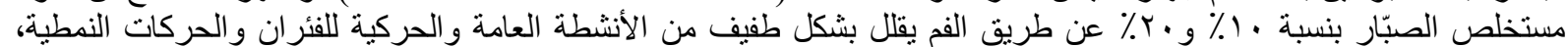

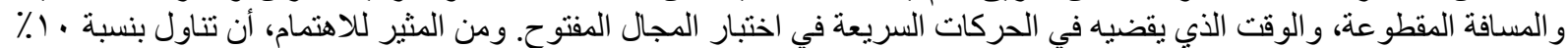

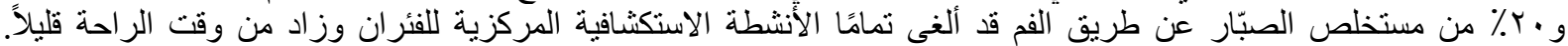

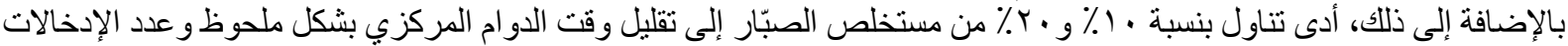

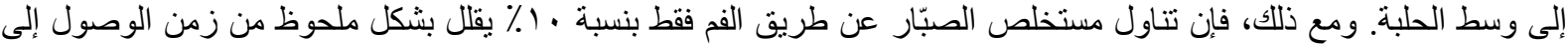

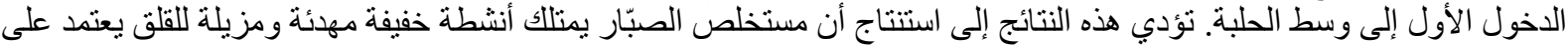

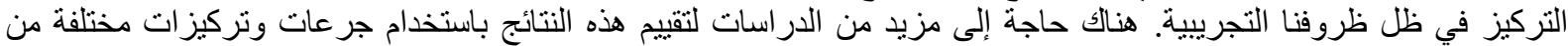
مستخلص الصبّار و غير ها من الاختبار ات السلوكية في الفئر ان. 